\title{
Working
}

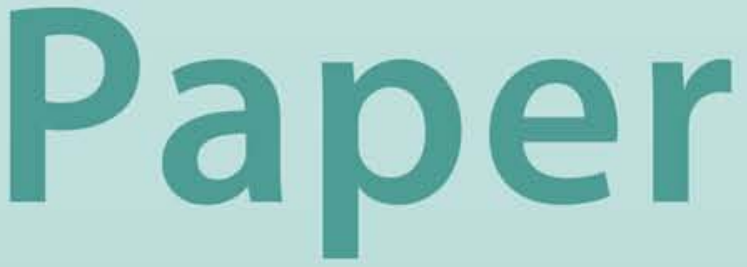




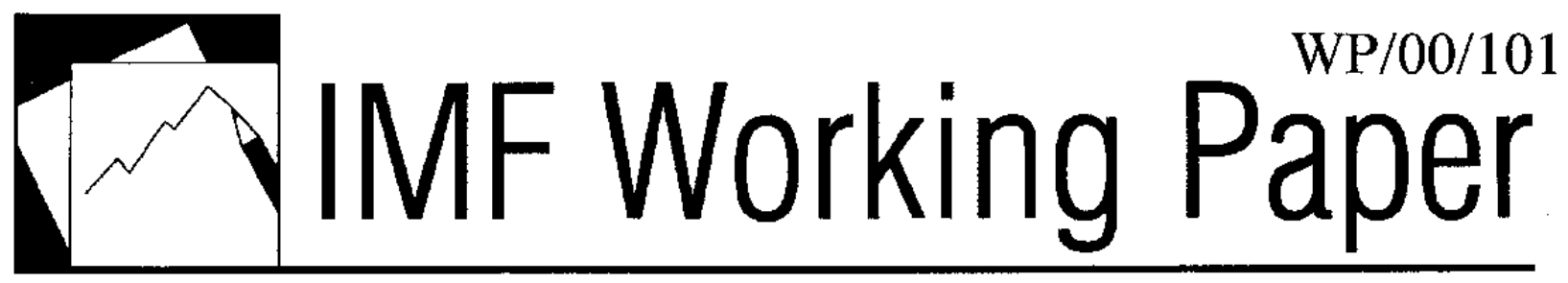

International Spillovers of Macroeconomic Shocks: A Quantitative Exploration

Douglas Laxton and Eswar S. Prasad 


\title{
IMF Working Paper
}

\author{
Research Department
}

\section{International Spillovers of Macroeconomic Shocks: A Quantitative Exploration}

\author{
Prepared by Douglas Laxton and Eswar S. Prasad ${ }^{1}$ \\ Authorized for distribution by Peter Isard
}

June 2000

\begin{abstract}
The views expressed in this Working Paper are those of the author(s) and do not necessarily represent those of the IMF or IMF policy. Working Papers describe research in progress by the author(s) and are published to elicit comments and to further debate.
\end{abstract}

This paper provides a quantitative exploration of international spillovers of macroeconomic shocks among the major industrial economies. The particular topical example analyzed here concerns the possible effects on the industrial economies of adverse shocks to the current U.S. economic expansion. The potential spillover effects of U.S. shocks to other industrial economies are found to be quite large. Extant economic conditions, particularly the low levels of nominal interest rates and the consequent possibility of liquidity traps in countries such as Japan, could significantly magnify these spillover effects.

JEL Classification Numbers: E32, E37, F42

Keywords: Macroeconomic shocks; international spillovers; nominal interest rate floor; macroeconometric simulations

Author's E-Mail Address: dlaxton@imf.org; eprasad@imf.org

${ }^{1}$ We are grateful to John Green, Graham Hacche, Flemming Larsen, Guy Meredith, Robert Tetlow, and Volker Wieland for helpful discussions and to Susanna Mursula for excellent research assistance. This paper is forthcoming in a conference volume entitled EMU, Financial Markets and the World Economy, Thomas Moser and Bernd Schips, eds. (Kluwer Academic Publishers). 


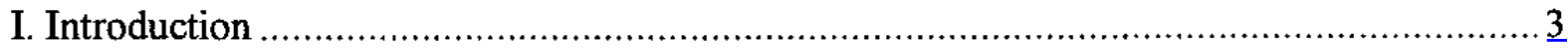

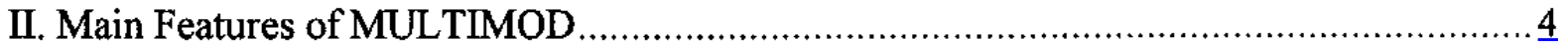

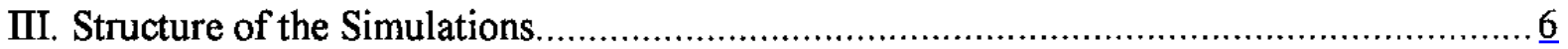

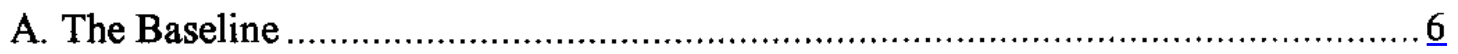

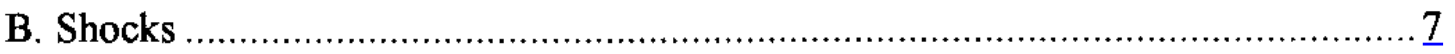

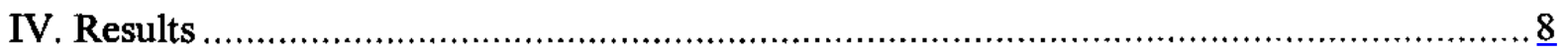

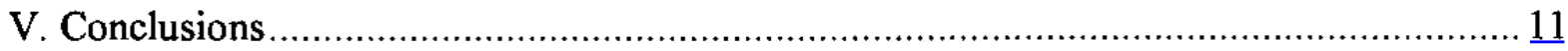

Tables

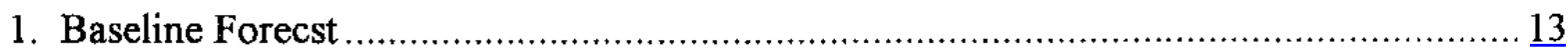

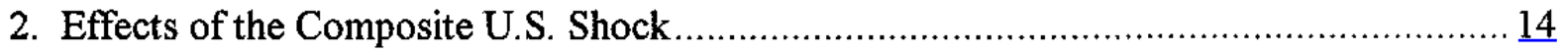

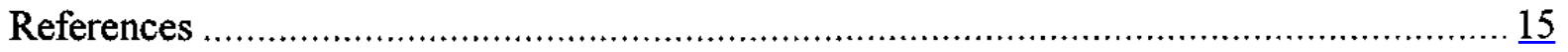




\section{INTRODUCTION}

The increasing integration of the world economy in recent decades, through trade and capital flows, is a well-documented phenomenon. Such integration has many advantages, including the benefits of specialization, enhanced diversification of country-specific risks, and the optimal allocation of capital investment. However, a corollary to this integration is the possibility of more rapid transmission of macroeconomic shocks across national borders. This has implications for the analysis of economic fluctuations in an international context (see, e.g., Lumsdaine and Prasad, 1997) as well as for the conduct of macroeconomic policy in response to exogenous shocks, either domestic or external.

This paper examines the possible international spillover effects of U.S. macroeconomic shocks, an issue that is of considerable topical importance in the context of the current economic situations of the main industrial economies. ${ }^{2}$ As of early 1999, the United States economy remains the engine of global growth, as it has been for much of 1998 . The Japanese economy remains mired in recession while most of the industrial economies of Europe continue to grapple with low growth and high unemployment. The U.S. expansion appears, in large part, to have been fueled by a persistent surge in private consumption, perhaps reflecting the increase in wealth implied by the boom in the stock market and driving private saving rates close to zero. The durability of high U.S. growth rates in a weak global economy remains suspect. The risks include uncertain prospects for the sustainability of U.S. stock market valuations at their current levels, of private saving rates at their historically low levels, of continued high investment rates and of rising current account imbalances.

Another crucial characteristic of current economic conditions is the prevalence of low levels of inflation and, in Europe and Japan, low nominal interest rates as well. Since nominal interest rates cannot drop below zero, the efficacy of standard monetary policy instruments is greatly diminished. An extreme example of this is the case of Japan, where short-term interest rates are virtually at the interest rate floor. The implications of this liquidity trap have been investigated for individual countries by numerous authors (see Krugman, 1998, for a prominent example).

This paper uses the IMF's multi-country macroeconometric model MULTIMOD to examine the possible repercussions on the global economy of certain risks to the U.S. expansion. The main innovation of this paper is that it provides a quantitative exploration of the international spillover effects of possible shocks to the U.S. economy. In particular, the paper shows how the nominal interest rate floor interacts with nonlinearities in the Phillips curve relationship to amplify these spillover effects. More generally, the paper provides a

${ }^{2}$ This paper was prepared for a conference held in March 1999. Not a great deal has changed over the last year in terms of the broad macroeconomic characterizations discussed in this paragraph. Experiments with updated data indicated that the main results in this paper remained qualitatively unchanged. 
quantitative characterization of the international spillovers of macroeconomic shocks through trade and other channels.

A key result of the paper is that the impact of domestic macroeconomic shocks to the U.S. economy on other industrial economies could in general be quite large and could be further amplified by the constellation of current economic conditions. Thus, the liquidity traps in Japan and other countries take on much greater international significance than in their respective domestic contexts. The paper examines the effects of these initial conditions on the spillovers of shocks. This analysis raises an interesting set of questions about the design of appropriate policy responses to such shocks, which are left for future research.

This paper is closely related to a recent burgeoning literature on the effects of the nominal interest rate floor on the conduct and effectiveness of monetary policy in a low inflation environment (see, e.g., Fuhrer and Madigan, 1997, Orphanides and Wieland, 1998, and Tetlow and Williams, 1998). Another contribution of this paper is the extension of this literature to a multi-country setting, allowing for international transmission effects. More importantly, unlike in most other papers, these issues are examined here in a fully specified dynamic model that incorporates the quasi-fiscal dimension of monetary policy, a comprehensive perspective that is critical for understanding the transmission mechanisms of and interactions among various aspects of macroeconomic policy (see Sims, 1998).

The next section of the paper describes the main features of the model. The nature of the simulation experiments is described in section III and the results are presented in section IV. Section V contains concluding remarks.

\section{Main Features of MULTIMOD}

This section provides a description of the main features of the model that is relevant for this paper. A more complete description of the model can be found in Laxton, Isard, Faruqee, Prasad and Turtelboom (1998). Detailed documentation and code for MULTIMOD can also be obtained at the IMF's external publications website (http://www.imf.org).

MULTIMOD is a general equilibrium macroeconometric model developed at the IMF to analyze the transmission of exogenous shocks and changes in macroeconomic policy within and across countries. The model is well suited for policy experiments since it incorporates forward-looking expectations and these expectations are imposed in a modelconsistent manner. The model derives a consistent path for all endogenous variables in response to exogenous shocks, while respecting stock-flow equilibrium conditions during the transition to the new steady state. MULTIMOD also has an explicit characterization of technology, household preferences, and other structural features, thereby making it possible to calibrate the model to replicate certain stylized facts in order to gain a better understanding of an economy's dynamic properties.

The model is not intended as a tool for making unconditional forecasts. Rather, MULTIMOD takes the World Economic Outlook (WEO) forecasts made by IMF country 
specialists as the baseline for simulation scenarios analyzing the effects of policy changes or other exogenous changes in the economic environment. The basic version of MULTIMOD is an annual model that includes each of the G-7 countries plus two country blocks that aggregate the small industrial countries and developing countries, respectively. For the purposes of this paper, the 11 countries participating in the first round of European Economic and Monetary Union (EMU) have been aggregated into one block.

In MULTIMOD, a monetary feedback rule based on money targeting is used to anchor nominal variables over the medium term, although this rule operates relatively more flexibly in the short run. In the short run, nominal money balances are adjusted to be consistent with changes in domestic absorption, interest rates and the price level. The monetary feedback rule is assumed to be credible and known to all agents. Given the low levels of nominal interest rates prevailing in many industrial economies, the simulations need to account for the existence of a nominal interest rate floor. One approach to address this issue would be to estimate a nonlinear money demand specification and insert it in the model. However, given the paucity of periods with low inflation and low nominal interest rates in the postwar sample for industrial countries, this proved infeasible. Hence, the simple and transparent approach taken here is to set a floor of zero on nominal interest rates. ${ }^{3}$

A second dimension in, which MULTIMOD is nonlinear, is the Phillips curve relationship, which allows for short-run inflation-unemployment trade-offs. ${ }^{4}$ This specification has important implications for the implied trade-off between inflation and unemployment at different levels of these variables and, therefore, for the conduct of monetary policy. A nonlinear short-run Phillips curve implies, for instance, that prompt actions to offset positive aggregate demand shocks can reduce the need for stronger compensating actions down the road to reduce inflationary pressures. On the other hand, in a situation characterized by excess supply, low inflation, and high unemployment, the real costs of negative aggregate demand shocks could be quite substantial. Under these circumstances, the nominal interest rate floor accentuates the tradeoff between current output stabilization and future inflation. In a world rife with uncertainty, including uncertainty about the levels of potential output and the output gap, the nonlinear Phillips curve places a premium on forward-looking and timely policy actions that could minimize the deleterious effects of exogenous shocks.

A feature of MULTIMOD that is critical for the analysis in this paper is that it explicitly recognizes the links between monetary and fiscal policy through their effects on

${ }^{3}$ See Chadha and Tsiddon (1996) for a theoretical analysis of the consequences of the nominal interest rate floor for monetary policy and its effects on output variability.

${ }^{4}$ Debelle and Laxton (1996) argue that, for certain G-7 countries, a nonlinear Phillips curve model fits the data better than linear models. The estimation methodology and estimates of the nonlinear Phillips curves for the industrial countries can be found in Laxton et. al. (1998). 
the government budget constraint. As Sims (1998) and others have argued, it is inappropriate to analyze these dimensions of macroeconomic policy in isolation. For instance, monetary policy has a quasi-fiscal dimension that is ignored in much of the literature but that is accounted for in MULTIMOD since money both enters the government budget constraint and affects real wealth (for details, see Laxton et. al., 1998). This feature is also important from a modeling perspective since models that do not capture these effects tend to display instability problems in response to adverse shocks at very low levels of inflation and nominal interest rates (see, e.g., Tetlow and Williams, 1998).

\section{STRUCTURE OF THE SimULATIONS}

The simulation results presented in this paper are deterministic simulations. The shocks to the model may be viewed as being unanticipated and, in the period in which they occur, economic agents are assumed to have full information about the shocks (and about the policy reaction functions). Moreover, the effects of the shocks are studied in a world where there are no responses to these shocks through standard macroeconomic policy instruments, including monetary and fiscal policy. MULTIMOD can, of course, be used to study the efficacy of specific policy responses to exogenous shocks, but these are not analyzed here since the main objective of this paper is to provide a quantitative characterization of the spillover effects of shocks.

As noted before, MULTIMOD is a tool designed to study the effects of shocks and policy measures relative to a baseline scenario that is based upon WEO forecasts for individual countries. Thus, the simulations reported here are all in the nature of "shock minus control" experiments. Before proceeding further, it is useful to examine the baseline for the simulations.

\section{A. The Baseline}

Table 1 shows the baseline forecasts for a set of key macroeconomic variables for the main industrial countries and industrial country blocks, based on the projections in the October 1998 World Economic Outlook. [The forecasts for 1999 are based partly on actual data and the simulations in this paper are therefore run from the year 2000.] [Tables will be updated when March 1999 WEO forecast becomes available; for now, 1999 data are also forecasts rather than actual data]. The second panel of the table shows the projections over the next 3 years. The last column shows medium-term projections that can be interpreted as abstracting from the effects of business cycle variations and, in the context of MULTIMOD, these reflect the steady-state levels or growth rates of the relevant variables. For instance, the medium-term projections of GDP growth rates reflect IMF estimates of the growth rates of potential output in the respective countries.

In 1998, growth in the United States clearly outpaced growth in the other industrial country blocks. Although the U.S. unemployment rate has fallen below conventional estimates of the NAIRU, inflation has remained low. The U.S. expansion has been sustained largely by robust private demand, with both private consumption and investment turning in 
strong growth during the current expansion. Correspondingly, the private saving rate has fallen to very low levels. The private saving-investment balance, as a ratio to GDP, was -3.8 percent in 1998. This implied that, despite a positive general government balance, the current account deficit, as a ratio to GDP, increased to 2.6 percent in 1998 and is forecast to rise further to 3 percent in 1999.

While actual output levels hover relatively close to potential output levels in the Euro area and in the other industrial countries, Japan has remained mired in recession. Private demand has collapsed and, but for the improvements in the trade balance, the growth performance would have been even worse. A crucial characteristic of this recession in Japan is that inflation has fallen close to zero and the short-term interest rate, the traditional instrument of monetary policy, has essentially hit the nominal interest rate floor. The prospect of deflation and the impotence of the interest rate instrument make this a critical time for the Japanese economy and, by extension, for the global economy. The analysis in this paper points to the extreme vulnerability of the Japanese economy, in its current situation, to external shocks.

The last column of this table shows the medium-term forecasts that can be interpreted as unconditional forecasts, given current policies, of macroeconomic variables in the industrial countries, abstracting from the effects of domestic and foreign business cycles. For instance, potential output growth rates are assumed to be on the order of 2.2 percent in much of the industrialized world. The inflation rate is assumed to stabilize at 2 percent. This medium-term inflation rate could also be viewed as the target of monetary policy. Hence, in our simulations, we experiment with different assumptions about this target. Another interesting feature of the medium-term forecast is that the U.S. current account deficit is expected to stabilize at around 1 percent of GDP, significantly lower than its current level, while the current account surpluses in the other industrial country blocks are expected to decline commensurately.

\section{B. Shocks}

The objective of this paper is to study the risks to the global economy arising from risks to the U.S. expansion. Hence, we consider a number of potential vulnerabilities in the U.S. economy and, while acknowledging that the magnitude of the shocks is a matter of debate, would argue that the probability of these shocks is rather high given current economic circumstances. We discuss in turn each of these shocks and how they are to be interpreted in the context of the model.

A number of observers have argued that valuations in the U.S. stock market are significantly out of line with price-earnings ratios, earnings projections and other fundamental determinants of stock market values. The equity premium is at historically low levels. Further, the increased flow of liquidity into U.S. stock markets, partly reflecting the effects of financial market distress elsewhere in the world, is unlikely to continue at current levels. Hence, a significant correction in stock market valuations is not unreasonable. 
Private fixed investment rates have remained high but, given the possibility of more moderate growth in the future, could be dampened over the short and medium term. We model this as a change in business confidence that feeds through directly into the investment equation. In addition to the wealth effects of a stock market correction, we also model a change in private consumption that is stimulated by a desire of economic agents to increase the private saving rate above its current level close to zero. In addition to these shocks to the U.S. economy, we consider a decline in commodity prices related to the slowdown in the growth of global aggregate demand.

Each of these shocks involves changes to the exogenous residuals of a particular equation. For instance, the shock to business confidence is modeled as a negative change in the "exogenous" residual of the investment equation. Rather than describe the shocks in terms of changes in these residuals, it is easier, for expository purposes, to describe the shocks in terms of the magnitudes of their effects on the particular variables of interest.

The stock market correction is assumed to change the total stock market capitalization in the United States by 30 percent. This is towards the high end of the possible overvaluation in the U.S. stock market that has been suggested by many financial market observers. The shock to business confidence in the investment equation translates into about a 6 percent decline in investment, upon impact, relative to the baseline. The shock to consumption reduces private consumption by 1.5 percent relative to baseline. This is sufficient to improve the private saving-investment balance by about 1 percent of GDP but the resulting deterioration in the government balance moderates this to a 0.5 percent improvement in the current account to GDP ratio. Thus, we have a menu of shocks that reflect the main risks to the short-term macroeconomic outlook for the United States.

The consumption shock, which reduces the average propensity to consume out of disposable income, is assumed to be permanent. The other shocks are assumed to be transitory and are gradually reduced to zero over the medium term. Thus, for instance, there are no exogenous shocks to the market capitalization of U.S. equity markets over the long term. But of course certain shocks analyzed here could, even if they are temporary, affect the steady state levels of certain variables in the model and thereby have permanent effects. More precise details on the magnitudes and persistence of the shocks are available from the authors upon request.

\section{Results}

Rather than present the effects of individual shocks, we focus on the combined effects of the shocks described in the previous section. This composite shock highlights most clearly the potential international spillovers of a set of large but plausible negative shocks to the U.S. economy. We then explore the sensitivity of the results to changes in the underlying economic conditions, i.e., and the initial conditions under which the experiment is run. Finally, the spillover effects of the individual shocks are discussed briefly. 
Table 2 shows the effects of the composite shock on the industrial economies. The responses are interpretable as deviations (in percent) from the baseline scenario and, in the cases of inflation, the unemployment rate, nominal interest rates, and the current account to GDP ratio, these deviations are expressed in percentage points. The first panel of this table shows the short-run responses of the key variables of interest in this exercise.

The impact effect of the composite shock is to reduce output, relative to baseline, by about 2 percent in the United States and by about 1 percent in Japan and the Euro area. In the United States, this output decline is generated by a contraction (again, relative to baseline) of almost 3.3 percent in domestic demand, as both consumption and investment weaken. The decline in short-term nominal interest rates feeds through into exchange rate depreciation. Coupled with the contraction in domestic demand, this leads to an improvement in the U.S. current account.

The importance of the trade channel for the international transmission of shocks becomes apparent in this exercise. Even though the shocks examined here all originate in the United States, the reversal in the U.S. current account deficit has a significant contractionary effect on output in the other industrial countries. The effects of the output contraction in the United States, which persist through the short-term forecast horizon, exert a negative effect on output in Japan and the Euro area over the 3-year period shown here, although the negative effects on other industrial countries last for only 1 year. In part, this difference can be attributed to the differences in initial conditions across these economic areas.

In Japan, the shock pushes the short-term interest rate practically all the way to the floor at zero. Further, given the low level of inflation in the baseline, the shock to growth essentially results in price deflation. In the Euro area and in the block of other industrial countries, the effects are mitigated, especially after the first year of the simulation, by the availability of greater room for maneuver in the short-term interest rate.

The key result to be taken from this simulation of shocks to the U.S. economy is the fragility of the current tepid recovery in the rest of the industrialized world and, given the macroeconomic conditions in these countries, their vulnerability to shocks that originate in the United States but that could be transmitted sharply and quickly across national borders.

At this juncture, a key question that arises is how important current economic circumstances in much of the industrialized world, particularly the low levels of inflation and nominal interest rates, are to the international transmission of shocks. To answer this question, we extend our simulations by using the WEO medium-term baseline forecast as the 
initial conditions for the simulations and then examine the effects of the same composite shock analyzed above. ${ }^{5}$

The second panel of Table 2 shows the effects of the composite shock relative to the medium-term baseline. The main result from this table is that the spillover effects of U.S. shocks on output in other industrial countries are markedly lower when the initial conditions are changed. Consider the case of Japan. The domestic short-term interest rate in Japan is projected to rise to about 6 percent over the medium term. ${ }^{6}$ Hence, in response to the U.S. composite shock, the interest rate can adjust much more than in current circumstances, thereby dampening the effects of the external shock on domestic demand. Further, given that the output gap has been eliminated in the medium-term baseline, the decline in the price level is not sufficient to push the economy into deflation. Consequently, the short-run decline in Japanese output is only about 0.3 percent. The short-run output effects in the Euro area are also much smaller under this scenario and close to zero for the block of other industrial countries. As a result, the second-round feedback effects on the U.S. economy through its trade links with other industrial economies are also smaller.

We also investigated the effects of each of the shocks individually. To conserve space, these results are not presented here but are available from the authors upon request. An interesting aspect of these results was that the output effects of the individual shocks summed up to less than the effects of the composite shock examined above. Moreover, this discrepancy was substantially smaller when we examined the effects of the individual shocks relative to the medium-term baseline. In other words, the spillover effects of shocks tend to be magnified when the shocks are contemporaneous and the effects of these mutually reinforcing shocks tends to be even stronger in an environment with large output gaps, low levels of inflation and, in particular, low levels of nominal interest rates.

In a different set of simulation experiments, we explored the sensitivity of the results to the choice of inflation target which, in the baseline, is set to 2 percent for all countries. ${ }^{7}$ Reducing the inflation target to 1 percent, for instance, significantly increased the short-run output costs of the composite U.S. shock in all countries. These results tie in with those of

\footnotetext{
${ }^{5}$ Operationally, this was done by taking the WEO forecast for the period $2010-2012$, by which time the effects of business cycle variations should be purged from the projections, and examining the effects of a similar composite shock in 2010 relative to that baseline.

${ }^{6}$ For the purposes of this paper, this interest rate projection should be viewed simply as an assumption that helps us highlight the quantitative importance of the nominal interest rate floor. Setting the baseline interest rate at this level virtually ensures that the floor will not be binding in terms of the interest rate response to even a large negative shock.

${ }^{7}$ These results are also available from the authors. We choose the same inflation target for all countries purely for convenience in running the simulations.
} 
Fuhrer and Madigan (1997), Orphanides and Wieland (1998) and others who find that the real costs of adverse shocks can be greater at low levels of inflation where the nominal interest rate floor becomes a tighter constraint.

Whether it is plausible that the types of shocks analyzed here could occur contemporaneously is open to debate. But, given the feedbacks between stock market performance and consumer and business confidence and the current uncertainties in the global economy, small shocks in one segment of the U.S. economy could well have significant impacts on other aspects of the domestic economy. Given the fragile state of the current macroeconomic environment in industrial countries, we would argue that the risks of these shocks, and their potential domestic and international spillovers, are not unreasonable and that policymakers should stand ready to respond decisively to such developments.

\section{CONCLUSIONS}

This paper has examined the international spillover effects of U.S. macroeconomic shocks on other industrial economies. As the world economy become more integrated, the transmission of shocks through trade and financial channels has important implications for the analysis of the spillover effects of domestic shocks on the global economy and for designing appropriate policy responses to counter the effects of such shocks.

The results in this paper show that shocks hitting an important industrial country such as the United States can have immediate and sharp effects on other industrial economies. Furthermore, the current economic circumstances in the industrial countries might impose significant constraints on the policy responses to adverse shocks. The particular example shown here illustrated how the nominal interest rate floor can magnify the global effects of adverse U.S. shocks.

The analysis in this paper raises a number of important questions about the appropriate policy responses to shocks, country-specific or otherwise, that can have a global impact. The trade-offs between current output growth (or unemployment) and future inflation, for instance, are an important consideration in designing and implementing effective monetary policy. MULTIMOD is designed precisely to answer questions of this sort and this is on the agenda for the next step of the research program initiated in this paper.

A complementary dimension along which this research needs to be extended is to explore these issues in a stochastic rather than deterministic environment. Authors such as Orphanides and Wieland (1998) have examined the consequences of the interest rate floor for the conduct of monetary policy in a stochastic environment, but in a closed economy model that is incomplete in that it ignores the fiscal dimensions of monetary policy. They find that inflation targets below a critical threshold could in fact influence the mean levels of real variables such as output growth and unemployment, rather than just their cyclical variability. We have provided, in this paper, a building block for addressing a richer set of questions such as the quantitative significance of the nominal interest rate floor in a stochastic 
environment that allows for the international transmission of shocks and that captures the interactions among different aspects of macroeconomic policy. 
Table 1. Baseline Forecast

\begin{tabular}{|c|c|c|c|c|c|c|}
\hline & & & & orecast & & Medium-term \\
\hline & 1998 & 1999 & 2000 & 2001 & 2002 & Forecast \\
\hline United States & & & & & & \\
\hline Real GDP growth & 3.85 & 3.05 & 2.20 & 2.18 & 2.15 & 2.15 \\
\hline Inflation & 1.01 & 1.16 & 1.96 & 2.25 & 2.25 & 2.00 \\
\hline Unemployment rate & 4.48 & 4.68 & 4.75 & 4.95 & 5.00 & 5.56 \\
\hline Short-term int. rate & 4.80 & 4.50 & 4.50 & 4.50 & 4.50 & 6.28 \\
\hline Long-term int. rate & 5.26 & 4.98 & 5.18 & 5.25 & 5.25 & 7.30 \\
\hline Nominal effective exchange rate $(1996=1)$ & 1.13 & 1.07 & 1.08 & 1.08 & 1.08 & 1.08 \\
\hline Current account balance/GDP & -2.54 & -3.17 & -2.92 & -2.64 & -2.44 & -0.99 \\
\hline Japan & & & & & & \\
\hline Real GDP growth & -2.79 & -1.07 & 0.30 & 2.99 & 3.57 & 2.15 \\
\hline Inflation & 0.24 & -0.72 & 0.22 & 0.24 & 0.37 & 2.00 \\
\hline Unemployment rate & 4.20 & 4.98 & 5.20 & 5.06 & 4.58 & 3.28 \\
\hline Short-term int. rate & 0.26 & 0.22 & 0.26 & 0.41 & 1.14 & 6.28 \\
\hline Long-term int. rate & 1.31 & 1.80 & 1.92 & 2.07 & 2.17 & 7.30 \\
\hline Nominal effective exchange rate $(1996=1)$ & 0.88 & 1.01 & 1.02 & 1.04 & 1.05 & 1.09 \\
\hline Current account balance/GDP & 3.41 & 3.47 & 3.00 & 2.70 & 2.54 & 1.51 \\
\hline Euro area & & & & & & \\
\hline Real GDP growth & 2.91 & 2.09 & 2.89 & 3,00 & 2.80 & 2.15 \\
\hline Inflation & 1.52 & 1.45 & 1.48 & 1.47 & 1.48 & 2.00 \\
\hline Unemployment rate & 11.64 & 11.33 & 10.99 & 10.55 & 10.18 & 3.28 \\
\hline Short-term int. rate & 3.87 & 2.93 & 3.01 & 3.36 & 3.79 & 6.28 \\
\hline Long-term int. rate & 4.74 & 4.07 & 4.26 & 4.56 & 4.76 & 7.30 \\
\hline Nominal effective exchange rate $(1996=1)$ & 0.92 & 0.94 & 0.96 & 0.96 & 0.97 & 1.09 \\
\hline Current account balance/GDP & 1.71 & 1.70 & 1.79 & 1.83 & 1.85 & 1.51 \\
\hline Other Industrial Countries & & & & & & \\
\hline Real GDP growth & 2.86 & 1.65 & 2.43 & 2.97 & 2.77 & 2.15 \\
\hline Inflation & 1.34 & 1.30 & 1.79 & 2.15 & 2.21 & 2.00 \\
\hline Unemployment rate & 6.40 & 6.36 & 6.47 & 6.36 & 6.31 & 6.59 \\
\hline Short-term int. rate & 6.03 & 5.05 & 4.80 & 4.84 & 4.65 & 6.28 \\
\hline Long-term int. rate & 5.35 & 5.02 & 5.12 & 5.16 & 5.17 & 7.30 \\
\hline Nominal effective exchange rate $(1996=1)$ & 1.03 & 0.99 & 0.97 & 0.95 & 0.94 & 0.92 \\
\hline Current account balance/GDP & -0.02 & 0.26 & 0.49 & 0.58 & 0.49 & 0.24 \\
\hline
\end{tabular}

Notes: The baseline forecast is based on the October 1998 version of the IMF's World Economic Outlook forecast. Inflation is measured on the basis of the GNP deflator. The Euro area block consists of the 11 countries participating in the first round of EMU. 
Table 2. Effects of the Composite U.S. Shock

\begin{tabular}{|c|c|c|c|c|c|c|}
\hline & 2000 & 2001 & 2002 & $\mathrm{~T}$ & $\mathrm{~T}+1$ & $\mathrm{~T}+2$ \\
\hline \multicolumn{7}{|l|}{ United States } \\
\hline Real GDP & -1.87 & -1.41 & -0.80 & -0.85 & -0.87 & -0.73 \\
\hline Inflation & -0.44 & -0.51 & -0.19 & -0.06 & 0.03 & 0.29 \\
\hline Unemployment rate & 0.63 & 0.36 & -0.10 & 0.21 & 0.06 & -0.20 \\
\hline Short-term int. rate & -0.26 & -0.99 & -1.71 & -0.15 & -0.49 & -0.77 \\
\hline Long-term int. rate & -0.57 & -0.44 & -0.24 & 0.24 & 0.40 & 0.56 \\
\hline Nominal effective exchange rate & -10.28 & -6.66 & -2.92 & -6.37 & -2.83 & 0.50 \\
\hline Current account balance/GDP & 0.86 & 1.82 & 2.38 & 0.88 & 1.72 & 2.10 \\
\hline \multicolumn{7}{|l|}{ Japan } \\
\hline Real GDP & -1.07 & -0.95 & -0.57 & -0.32 & -0.16 & -0.01 \\
\hline Inflation & -0.46 & -0.78 & -0.90 & -0.47 & -0.77 & -0.88 \\
\hline Unemployment rate & 0.06 & 0.09 & 0.10 & 0.02 & 0.03 & 0.03 \\
\hline Short-term int. rate & -0.26 & -0.41 & -1.14 & -0.65 & -1.15 & -1.51 \\
\hline Long-term int. rate & -1.14 & -1.10 & -1.02 & -1.03 & -0.96 & -0.83 \\
\hline Nominal effective exchange rate & 16.10 & 12.41 & 8.23 & 11.91 & 9.05 & 6.29 \\
\hline Current account balance/GDP & -0.66 & -1.28 & -1.72 & -0.44 & -0.97 & -1.25 \\
\hline \multicolumn{7}{|l|}{ Euro area } \\
\hline Real GDP & -1.16 & -0.58 & -0.43 & -0.94 & -0.38 & -0.26 \\
\hline Inflation & -0.38 & -0.67 & -0.86 & -0.42 & -0.70 & -0.84 \\
\hline Unemployment rate & 0.31 & 0.33 & 0.33 & 0.25 & 0.25 & 0.25 \\
\hline Short-term int. rate & -0.81 & -1.33 & -1.64 & -0.83 & -1.31 & -1.56 \\
\hline Long-term int. rate & -1.37 & -1.33 & -1.20 & -1.23 & -1.16 & -1.03 \\
\hline Nominal effective exchange rate & 10.44 & 8.46 & 6.20 & 8.79 & 6.96 & 4.99 \\
\hline Current account balance/GDP & -0.39 & -0.67 & -0.97 & -0.29 & -0.62 & -0.89 \\
\hline \multicolumn{7}{|l|}{ Other Industrial Countries } \\
\hline Real GDP & -0.34 & 0.61 & 0.73 & 0.00 & 0.65 & 0.57 \\
\hline Inflation & -0.27 & -0.27 & -0.30 & 0.02 & 0.06 & -0.02 \\
\hline Unemployment rate & 0.19 & 0.03 & 0.01 & 0.05 & -0.09 & -0.05 \\
\hline Short-term int. rate & -2.23 & -3.37 & -3.54 & -2.03 & -2.90 & -2.97 \\
\hline Long-term int. rate & -2.14 & -1.93 & -1.61 & -1.86 & -1.70 & -1.43 \\
\hline Nominal effective exchange rate & -6.02 & -5.89 & -5.31 & -6.29 & -6.33 & -6.04 \\
\hline Current account balance/GDP & -1.72 & -2.53 & -2.59 & -1.63 & -2.46 & -2.49 \\
\hline
\end{tabular}

Notes: The deviations relative to baseline are expressed in percentage points for inflation, the unemployment rate, the interest rates and the current account to GDP ratio and in percent for output and the nominal effective exchange rate. Inflation is measured on the basis of the GNP deflator. The second panel shows the results from the simulations that use the medium-term forecast as the baseline. 


\section{References}

Akerlof, G. A., W. T. Dickens, and G. L. Perry, 1996, "The Macroeconomics of Low Inflation," Brookings Papers on Economic Activity, Vol. 1, pp. 1-76.

Chadha, B. and D. Tsiddon, 1996, "Inflation, Nominal Interest Rates, and the Variability of Output," IMF Working Paper 96/109 (Washington: International Monetary Fund).

Debelle, G. and D. Laxton, 1996, "Is the Phillips Curve Really a Curve? Some Evidence for Canada, the United Kingdom, and the United States," IMF Working Paper 96/111 (Washington: International Monetary Fund).

Fuhrer, J. C. and B. Madigan, 1997, "Monetary Policy when Interest Rates are Bounded at Zero," Review of Economics and Statistics, Vol. 79 (November), pp. 573-85.

Krugman, P., 1998, "Japan's Trap," unpublished mimeograph available via the Internet at http://web.mit.edu/krugman/www/japtrap.html.

Laxton, D. and E. S. Prasad, 1997, "Possible Effects of European Monetary Union on Switzerland: A Case Study of Policy Dilemmas Caused by Low Inflation and the Nominal Interest Rate Floor," IMF Working Paper 97-23, (Washington: International Monetary Fund). Forthcoming in Journal of Policy Modeling.

Laxton, D., G. Meredith, and D. Rose, 1995, "Asymmetric Effects of Economic Activity on Inflation," Staff Papers, International Monetary Fund, Vol. 42, No. 2.

Laxton, D., P. Isard, H. Faruqee, E. Prasad, and B. Turtelboom, 1998, "MULTIMOD Mark III: The Core Dynamic and Steady-State Models," IMF Occasional Paper No.164, (Washington: International Monetary Fund).

Lumsdaine R. L. and E. S. Prasad, 1997, "Identifying the Common Component in International Economic Fluctuations," National Bureau of Economic Research, Working Paper No. 5984.

Meredith G., 1998, "REPMOD: A Smaller Sibling for MULTIMOD,” manuscript, International Monetary Fund.

Orphanides, A. and V. Wieland, 1998, "Price Stability and Monetary Policy Effectiveness when Nominal Interest Rates are Bounded at Zero," Finance and Economics Discussion Series Paper No. 1998-35, Board of Governors of the Federal Reserve System.

Tetlow, R. and J.C. Williams, 1998, "Implementing Price Stability: Bounds, Boundaries and Inflation Targeting," paper presented at the CEPR/FRBSF Conference on Inflation. 